a doctrine whose working hypothesis is a chameleon-like ability to avoid refutation should appeal as much to a metaphysician as to an anti-metaphysician). What I dispute is that modern physics necessarily supports such a view or can progress from it.

The first point to be made is that indeterminism in quantum physics does not, of itself, call for a new epistemology. Bergstein seems to imply that it does, for, although he develops the idea of complementarity of language as an independent philosophical principle, he then adds ". . . (philosophers) have not yet realized how profoundly the discoveries of modern physies affect the whole of epistemology". To say this is to imply that the uncertainty principle has a meaning which transcends quantum physics. But this is precisely what is in dispute. What the uncertainty principle tells us is that our knowledge of nature is limited by the existing language of physics. It does not limit all that we can ever know unless the existing language is the only possible one. What Bergstein argues is that the existing language"ordinary" language-is so inextricably bound up with our experience that any other language would be unthinkable, even meaningless. But this is an independent assertion which cannot be inferred from quantum physics.

The notion that "ordinary language is the ultimate source of the unambiguousness of physical description" seems to me to be a very restrictive hypothesis which is not evinced by scientific history. Relativity, for example, was opposed by philosophers on the ground that Euclidean space was part of everyday experience and therefore Riemannian space was unthinkable. Of course, one can argue (with hindsight) that the example is not a good one because both theories employ the same variables; but it would be absurd to suggest that the everyday meaning of time has not been modified.

Although Bergstein regards ordinary language (and complementarity in it) as unavoidable, he does not, however, exclude the possibility of physical theory beyond quantum mechanies. He is prepared (as many who are otherwise his co-idcologists are not) for "a more fundamental theory of matter and radiation which will contain quantum mechanics as an inherent sub-section". If by this he means "a more detailed theory", then he is being inconsistent. For, as Bohm has pointed out, such a theory is equivalent to an assumption of hidden variables. And, since these variables have not yet been observed, they will not be part of ordinary language. If he means "a logical extension of quantum theory" he should say so. But it is not clear what kind of extension can be meaningful in the face of an irreducible complementarity.

Perhaps the way out of the difficulty is to relegate complementarity from the level of a fundamental principle to that of a heuristic description, as Landé has suggested. After all, the discoveries of modern physics were not revealed by complementarity in language, but by experiments designed as if there is an external world independent of what we think. It is this ontological view which has motivated science from Galileo to Einstein. But then motivation is also "no problem for the paper philosopher".

$$
\text { Yours faithfully, }
$$

Department of Chemistry,

\section{P. Melrose}

King's College,

Strand, London WC2.

Corrighnduxi. In the article "Multiple Forms of Rat Brain Monoamine Oxidase" by Youdim, Collins and Sadler (Nature, 223, 626; 1969), the cathodes and anodes should be interchanged in Fig. 1, and lines 3-4 of the legend should read " $\mathrm{MAO}_{1^{-3}}$ migrated from cathode to anode and $\mathrm{MAO}_{4}$ from anode to cathode".

\section{International Meetings}

September 1-4, Group Conflict and Mutual Acceptance, San Francisco (Professor H. A. Enzer, Hofstra University, Hempstead, New York 11550).

September 1-5, British Pharmaceutical Conference, Belfast (Pharmaceutical Society of Great Britain, 17 Bloomsbury Square, London WC1).

September 2-6, International Congress of Cybernetics, London (Dr J. Rose, International Congress of Cybernetics, c/o Blackburn College of Technology and Design, Blackburn BB2 1LH, Lancashire, UK).

September 4-5, British Pharmacological Society Meeting, Manchester (Dr G. E. Mawer, Department of Pharmacology, Medical School, Oxford Road, Manchester 13, M13 9PL, UK).

September 15-17, Social Demography and Medical Responsibility, Budapest (Regional Secretary, International Planned Parenthood Federation, Europe and Near Fast Region, 64 Sloane Street, London SW1).

September 19-20, Application of Microchemical Techniques in the Petrochemical and Allied Industries, Portsmouth (Society for Analytical Chemistry, 9-10 Savile Row, London WIX 1AF).

September 24-27, Diamond Conference, Reading (Professor C. W. McCombie, Department of Physics, The University, Whiteknights, Reading, Berkshire, UK).

September 25-26, Optimum Population for Britain, London (Institute of Biology, 41 Queen's Gate, London SW7).

September 25-26, Biochemical Society Meeting, Cardiff (Biochemical Society, 7 Warwick Court, Holborn, London WC1).

September 30-October 3, Non-Silver Photographic Processes, Oxford (Mr C. Roberts, Kodak Research Laboratories, Wealdstone, Harrow, Middlesex, UK).

October 2-3, Autoimmunity Phenomena, Paris (Société Française d'Immunologie, Institut Pasteur, 28 Rue du Docteur Roux, Paris 15e, France).

\section{Sabbatical Itinerants}

In the hope of providing some practical assistance in the good cause of mobility between laboratories, Nature advertises the needs for housing of families about to take up periods of sabbatical leave. To begin with, no charge will be made for advertisements like this. It is hoped that a period of experiment will show what form these advertisements could most usefully take and whether they are effective.

Wanted: Furnished accommodation for 12 months from October 1969, within reasonable distance of Oxford, for English speaking young Swiss family of 3. Please contact Dr Max Dobler, Laboratorium für Organische Chemie, Eidg. Technische Hochschule, Universitätsstrasse 6, 8006 Zürich, Switzerland.

Wanted: Furnished, centrally heated house in the country in the south of England for entomologist and family of 2 school-age children. Returning for 1 year in February 1970 for writing up. Please contact R. A. Farrow, OICMA (International African Migratory Locust Organization), Kara, Macina, Mali.

Vacant: Spacious furnished apartment with 4 bedrooms, central heating and garden, in central Edinburgh, for 1 year from October 1969. Please contact N. Stebbing, Department of Zoology, West Mains Road, University of Edinburgh, Scotland. 